\title{
Video Article \\ Optimized Analysis of DNA Methylation and Gene Expression from Small, Anatomically-defined Areas of the Brain
}

\author{
Marc Bettscheider ${ }^{1}$, Arleta Kuczynska ${ }^{1}$, Osborne Almeida ${ }^{1}$, Dietmar Spengler ${ }^{1}$ \\ ${ }^{1}$ Max Planck Institute of Psychiatry
}

Correspondence to: Dietmar Spengler at spengler@mpipsykl.mpg.de

URL: https://www.jove.com/video/3938

DOI: doi:10.3791/3938

Keywords: Neuroscience, Issue 65, Genetics, Physiology, Epigenetics, DNA methylation, early-life stress, maternal separation, bisulfite sequencing Date Published: 7/12/2012

Citation: Bettscheider, M., Kuczynska, A., Almeida, O., Spengler, D. Optimized Analysis of DNA Methylation and Gene Expression from Small, Anatomically-defined Areas of the Brain. J. Vis. Exp. (65), e3938, doi:10.3791/3938 (2012).

\section{Abstract}

Exposure to diet, drugs and early life adversity during sensitive windows of life ${ }^{1,2}$ can lead to lasting changes in gene expression that contribute to the display of physiological and behavioural phenotypes. Such environmental programming is likely to increase the susceptibility to metabolic, cardiovascular and mental diseases ${ }^{3,4}$.

DNA methylation and histone modifications are considered key processes in the mediation of the gene-environment dialogue and appear also to underlay environmental programming ${ }^{5}$. In mammals, DNA methylation typically comprises the covalent addition of a methyl group at the 5 position of cytosine within the context of $\mathrm{CpG}$ dinucleotides.

CpG methylation occurs in a highly tissue- and cell-specific manner making it a challenge to study discrete, small regions of the brain where cellular heterogeneity is high and tissue quantity limited. Moreover, because gene expression and methylation are closely linked events, increased value can be gained by comparing both parameters in the same sample.

Here, a step-by-step protocol (Figure 1) for the investigation of epigenetic programming in the brain is presented using the 'maternal separation' paradigm of early life adversity for illustrative purposes. The protocol describes the preparation of micropunches from differentially-aged mouse brains from which DNA and RNA can be simultaneously isolated, thus allowing DNA methylation and gene expression analyses in the same sample.

\section{Video Link}

The video component of this article can be found at https://www.jove.com/video/3938/

\section{Protocol}

\section{Programming by Early Life Adversity}

Maternal separation (MS) is performed to induce early-life stress (ELS) in pups delivered by timed-pregnant C57BL/6N mice (postnatal day 0 (P0) on day of birth).

1. Individual litters are placed in clean cages (with heating pad) for $3 \mathrm{~h}$ daily from P1-10.

2. Control (non-ELS) pups remain undisturbed in the maternal nest throughout.

3. Pups are kept with their mothers until weaning (P21), after which time they are housed in sex-matched groups (3-5 mice per cage) under standard laboratory animal housing conditions.

\section{Isolation and Dissection of Brain Tissue}

1. Mice are killed at desired ages by cervical dislocation. Note: because this protocol involves a stress paradigm, no anesthesia is given prior to cervical dislocation, to avoid interfering with normal physiological regulation of stress hormones. Skulls are opened and brains are carefully removed and immediately snap-frozen by immersion in iso-pentane-dry ice, before being stored at $-80^{\circ} \mathrm{C}$.

2. Brains are cryosectioned ( $10 \mu \mathrm{m}$ thickness); sections are mounted on Superfrost glass slides and maintained at $-20^{\circ} \mathrm{C}$. Reference to a standard mouse stereotaxic atlas (e.g. Paxinos ${ }^{6}$ ) is used to verify anatomical precision and to ensure inclusion of the region of interest (e.g. for neurons in the paraventricular nucleus - PVN - collect sections starting at the level of the rostral PVN, bregma -0.75 to -0.85 ).

3. Sections are stained with cresyl violet to facilitate identification of different brain structures. Punches $(0.8 \mathrm{~mm})$ of the regions of interest (e.g. PVN) are obtained by in loco microdissection. 


\section{Nucleic Acid Extraction from Brain Punches}

An optimized protocol for simultaneously extracting DNA and RNA from tiny neuroanatomically-defined brain regions for bisulfite and gene expression analyses is described ${ }^{7}$.

Note: Considering that RNA is less stable than DNA in the GTC-Buffer, we recommend processing RNA first. The homogenate used for DNA purification can be kept at room temperature (RT) during that time.

1. Homogenize punches using a pipette and vortexer in $400 \mu \mathrm{l}$ of guanidinium thiocyanate (GTC) buffer (4.5 M guanidinium thiocyanate, $2 \% \mathrm{~N}$ -

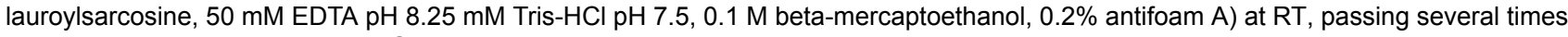
through a hypodermic syringe (29G) (Figure 2).

2. Split lysate into equal parts; both RNA and DNA may be extracted at the same time or separately, depending on particular experimental needs.

3. For RNA purification add $1 / 10$ volume of NaOAc, 1 volume AquaPhenol (Appligene) (pH 4) and 1/2 volume of chloroform:isoamyl (24:1) to lysate. Vortex vigorously after each step and incubate on ice for $10 \mathrm{~min}$, centrifuge (20 min at $10,000 \mathrm{~g}$ at $\left.4{ }^{\circ} \mathrm{C}\right)$; add an equal volume of $70 \%$ EtOH to aequous phase.

4. Transfer mixture to an RNA spin column (e.g. Nucleospin RNA II from Macherey-Nagel) and perform on-column DNase-digestion and washing steps (follow manufacturer's protocol); elute RNA in $25 \mu \mathrm{l} \mathrm{H}_{2} \mathrm{O}$.

5. For DNA purification an optimized protocol of the Qiagen DNeasy Blood and Tissue Kit is used. Equilibrate lysate with equal volumes of Buffer $\mathrm{AL}$ and $100 \% \mathrm{EtOH}$, load on a Spin Column centrifuge (1 min at 10,000 g at RT) and discard flow-through.

6. Add $500 \mu \mathrm{l}$ Buffer AW1 including $5 \mu \mathrm{l}$ RNAse $(1 \mathrm{mg} / \mathrm{ml})$ to column and incubate $10 \mathrm{~min}$ at RT. Spin (1 min at 10,000 g, RT) and discard flowthrough.

7. Wash column with $500 \mu \mathrm{l}$ Buffer AW2, discard flow-through and spin-dry empty column (1 min at 15,000 g).

8. Add prewarmed $\left(70^{\circ} \mathrm{C}\right)$ Buffer $\mathrm{AE}$ and incubate columns for $10 \mathrm{~min}$ at $70{ }^{\circ} \mathrm{C}$. Elute by centrifugation $(1 \mathrm{~min}, 10,000 \mathrm{~g})$, re-apply flow-through and repeat centrifugation step.

Use a spectrophotometer to determine DNA and RNA concentrations. A typical PVN punch yields $\sim 600$ ng DNA and $\sim 400$ ng RNA. For gene expression analysis by quantitative PCR (qPCR), we typically use $\sim 100 \mathrm{ng}$ of RNA in the reverse transcription reaction.

\section{Bisulfite Conversion}

Sodium Bisulfite is used to convert non-methylated cytosines to uracils. In contrast, methylated cytosines are protected from conversion. Therefore, all cytosines that are detected in the final sequencing of the bisulfite PCR-amplicon represent methylated cytosines.

Bisulfite conversion causes substantial DNA degradation which can be a limiting factor in PCR analysis. Optimized reaction conditions that maximize cytosine conversion, reduce DNA fragmentation and maintain single-stranded DNA even at lower temperatures can be achieved using Qiagen's EpiTect Bisulfite Kit. In our hands $\sim 200 \mathrm{ng}$ of DNA purified from micropunches provide a sufficient amount of starting material for the bisulfite reaction.

To prevent differences in the efficiency of the conversion reaction, the amount of template DNA should be kept constant among all samples processed during an experiment. In addition, sequence reads should be scrutinized for conversion efficiency by examining the rate of nonconverted non-CpGs. This rate should exceed $98 \%$. Lower values indicate incomplete or inefficient bisulfite conversion and the underlying sequences should be excluded from the analysis.

\section{Bisulfite PCR}

1. Design bisulfite sequencing primers that are specific to bisulfite converted DNA (see discussion); Methyl Primer Express software (https:// products.appliedbiosystems.com/ab/en/US/adirect/ab?cmd=catNavigate2\&catID=602121) will aid this and help to determine optimal annealing temperatures in pilot experiments.

2. Prepare PCR-Master-Mix (for one reaction) as follows:

$2.5 \mu \mathrm{l}$ 10x PCR buffer

$0.5 \mu \mathrm{l} 10 \mathrm{mM}$ dNTPs

$1 \mu \mathrm{l} 10 \mu \mathrm{M}$ forward primer

$1 \mu \mathrm{l} 10 \mu \mathrm{M}$ reverse primer

$0.125 \mu \mathrm{l}$ Qiagen Hotstart Taq Plus

fill up to $23 \mu$ with $\mathrm{H}_{2} \mathrm{O}$

3. Add $2 \mu \mathrm{l}$ bisulfite-treated DNA to reaction.

4. Amplify using the following conditions:

1 cycle $6 \min 95^{\circ} \mathrm{C}$

$45-50$ cycles of $1 \mathrm{~min} 95^{\circ} \mathrm{C}, 1 \mathrm{~min}$ at optimal annealing temperature, $1 \mathrm{~min} 72{ }^{\circ} \mathrm{C}$

1 cycle $5 \min 72{ }^{\circ} \mathrm{C}$

Analyze $7 \mu \mathrm{l}$ of PCR product by agarose gel electrophoresis to verify size of the amplicon and purify remaining PCR reaction for subsequent ligation using a commercially available PCR clean-up kit (e.g. Macherey-Nagel Nucleospin Extract). In case additional undesired PCR products are obtained, gel purification is recommended. 


\section{Bisulfite Sequencing}

High-resolution DNA methylation profiles deduced from single clone readings can detect small changes in DNA methylation and identify regulatory regions that are responsive to treatment (environmental programming). The bisulfite sequencing process comprises three consecutive working steps. Firstly, PCR products obtained by prior bisulfite PCR are ligated into a vector and transformed into bacteria. Secondly, colony PCR from single clones is employed to determine the correct size of the insert. Thirdly, positive colony PCRs are cleaned up and subjected to Big-Dye sequencing reaction. Following a clean-up step, products are electrophoresed on a capillary sequencer.

\subsection{Ligation and Transformation}

Note: We routinely use the pGEM-T vector cloning kit (Promega). In our experience, the cloning efficiency depends critically on the insert to be ligated. Different vectors should be tested in case low numbers of recombinant clones are repeatedly obtained.

1. Set up ligation reaction:

$5 \mu \mathrm{l} 2 \mathrm{x}$ Ligation Buffer

$1 \mu \mathrm{l} \mathrm{pGEM-T} \mathrm{Vector}$

$1 \mu \mathrm{l}$ T4-Ligase

$3 \mu$ l cleaned-up PCR product

2. Mix reaction by pipetting and incubate over night at $4{ }^{\circ} \mathrm{C}$.

Note: Ligation may also be carried out for $1 \mathrm{~h}$ at RT as well. To increase number of recombinant clones, over night ligation at $4{ }^{\circ} \mathrm{C}$ is preferred.

3. Clean-up of ligation products by ethanol precipitation:

a. Add $1 \mu$ glycogen, $1 \mu \mathrm{l} 3 \mathrm{M} \mathrm{NaAc}$ and $25 \mu \mathrm{l} 100 \% \mathrm{EtOH}$ to the ligation reaction and precipitate for 1 min in liquid nitrogen.

b. Centrifuge $\left(15,0000 \mathrm{~g}\right.$ for $30 \mathrm{~min}$ at $\left.4{ }^{\circ} \mathrm{C}\right)$ and discard supernatant.

c. Wash with $300 \mu \mathrm{l} 70 \% \mathrm{EtOH}$ and centrifuge $\left(15,000 \mathrm{~g}\right.$ for $20 \mathrm{~min}$ at $\left.4{ }^{\circ} \mathrm{C}\right)$, discard supernatant and dry pellet at RT (10 min).

d. Resuspend pellet in $10 \mu \mathrm{l} \mathrm{H}_{2} \mathrm{O}$.

\subsection{Transformation of ligation products in electrocompetent bacteria}

1. Precool electroporation cuvettes ( $1 \mathrm{~mm}$ width) on ice and thaw aliquot of electrocompetent $\mathrm{DH} 5 \mathrm{a}$ bacteria on ice.

2. Add $45 \mu \mathrm{l} \mathrm{DH5a} \mathrm{bacteria} \mathrm{to} 10 \mu \mathrm{l}$ cleaned up ligation product (see above) and transfer to cuvette.

3. Transform bacteria at $1.5 \mathrm{kV}, 200 \Omega, 15 \mu \mathrm{F}$ and add $1 \mathrm{ml}$ of prewarmed SOB medium directly after pulse delivery.

4. Recover bacteria for $1 \mathrm{~h}$ at $37^{\circ} \mathrm{C}$, spread $100 \mu$ l of suspension on LB/ampicillin plates coated with IPTG/X-Gal.

5. Incubate plates overnight at $37^{\circ} \mathrm{C}$.

\subsection{Colony PCR}

Note: Colony PCR from single clones is conducted to ensure that inserts are of predicted size. Delayed color development from the blue/white screening, undesired recombination events during ligation, incorporation of oligomeric primer pairs or truncated PCR products may otherwise lead to faulty sequencing results. We routinely use T7 and SP6 primers to amplify cloned inserts; this approach results in additional vector sequences of approximately $150 \mathrm{bp}$. T7 primer is used in the sequencing reaction in a later step.

1. Set up colony PCR reaction in 96-well plate. For one reaction use:

$3 \mu \mathrm{l} 2.5 \mathrm{mM} \mathrm{MgCl} 2$

$2.5 \mu \mathrm{l} 10 \mathrm{x}$ Taq buffer

$1.5 \mu \mathrm{l} 10 \mathrm{mM}$ dNTP

$2 \mu \mathrm{l} 2.5 \mathrm{mM}$ T7 primer

$2 \mu \mathrm{l} 2.5 \mathrm{mM}$ SP6 primer

$1 \mu$ Fermentas Taq Polymerase

fill up to $25 \mu \mathrm{l}$ with $\mathrm{H}_{2} \mathrm{O}$

2. Dispense $25 \mu \mathrm{l} /$ well of master mix into each well of a 96 -well plate.

3. Pick positive (white) clone from plate with pipette tip and dip into PCR reaction.

4. Amplify using following conditions:

1 cycle 4 min at $95^{\circ} \mathrm{C}$

10 cycles $30 \mathrm{~s}$ at $94^{\circ} \mathrm{C}, 30 \mathrm{~s}$ at $56^{\circ} \mathrm{C}$ and $30 \mathrm{~s}$ at $72^{\circ} \mathrm{C}$

30 cycles $30 \mathrm{~s}$ at $94^{\circ} \mathrm{C}, 30 \mathrm{~s}$ at $48^{\circ} \mathrm{C}$ and $30 \mathrm{~s}$ at $72^{\circ} \mathrm{C}$

1 cycle 5 min at $72{ }^{\circ} \mathrm{C}$

5. Load $5 \mu \mathrm{l}$ of colony PCR on an agarose gel and determine reactions that contain the right insert size.

6. Colony PCRs containing the desired amplicons are cleaned up using a commercially available kit (Machery Nagel Nucleofast).

\subsection{Big-Dye terminator reaction and sequencing}

1. Prepare Master mix for Big-Dye reaction. For one reaction use:

$1 \mu \mathrm{H} \mathrm{H}_{2} \mathrm{O}$

$0.5 \mu \mathrm{l} \mathrm{Big-Dye} \mathrm{reagent}$

$1.5 \mu \mathrm{l}$ Sequencing buffer

2. Dispense $3 \mu \mathrm{l} /$ well into each well of a 96 -well plate, to each well add $2 \mu \mathrm{l}$ of cleaned up colony PCR product and run reaction on a thermocycler with the following parameters:

1 cycle 1 min at $96{ }^{\circ} \mathrm{C}$

35 cycles of $10 \mathrm{~s}$ at $96^{\circ} \mathrm{C}, 5 \mathrm{~s}$ at $50^{\circ} \mathrm{C}$ and $4 \min$ at $60^{\circ} \mathrm{C}$ 
3. The Big-Dye reaction is cleaned up using a commercial kit (Millipore Montage 96 Sequencing Clean-Up Kit) and processed on a capillary sequencer (e.g. ABI 3100 DNA).

4. Sequences are analyzed using the Biq Analyzer (http://biq-analyzer.bioinf.mpi-sb.mpg.de/) or the online tool BISMA (http://biochem.jacobsuniversity.de/BDPC/BISMA/) to derive the methylation pattern of the investigated DNA region (Figure 4).

\section{Representative Results}

To gain insight into the influence of ELS on the Avp expression and methylation status, C57BL/6N mice were processed according to the workflow described above. Briefly, a group of C57BL/6N mice was subjected to ELS while the control group was left undisturbed. The PVN and the supraoptic nucleus (SON) were punched and DNA and RNA were isolated simultaneously from the single punches. RNA was reverse transcribed and the levels of Avp transcripts were measured by qPCR analysis and normalized to the expression of $H p r t$ and Gapdh housekeeping genes. DNA was bisulfite treated, amplified with primers specific to the Avp enhancer (Figure 4a) and the PCR products were cloned and sequenced. At least 20 recombinant clones from each mouse/PCR were analyzed to determine methylation frequencies for the $\mathrm{CpGs}$ contained in the PCR amplicon (Figure 4b). Compared to controls, ELS induced a significant hypomethylation at CpG10, CpG12, CpG13 and Cpg14 of the Avp enhancer ( $p<0.05, n=6-8$ animals) suggesting epigenetic marking of this regulatory region through early-life experiences. In contrast to the PVN, methylation of the Avp enhancer was unaffected by ELS in the SON illustrating tissue specificity of epigenetic marking (Figure 4c). Analysis of the DNA methylation status at CpG10 and Avp gene expression in control animals $(\mathrm{n}=6)$ evidenced a negative correlation pointing to a role of DNA methylation in the fine-tuning of AVP gene expression (Figure 4d).

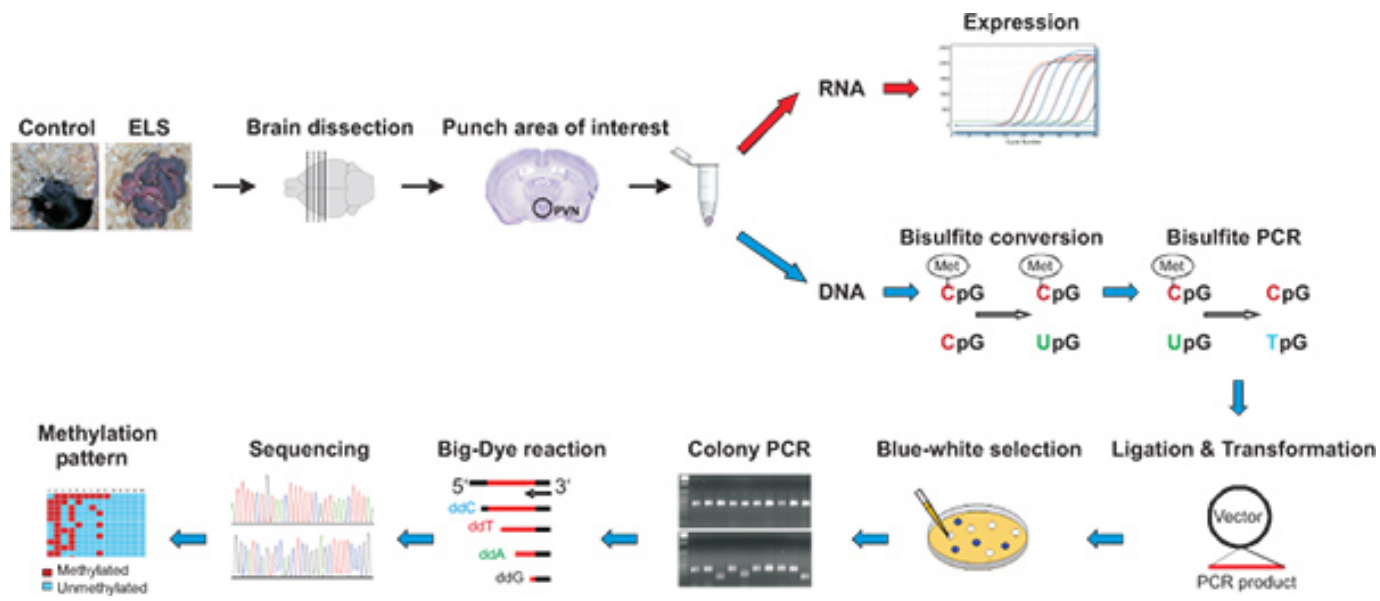

Figure 1. Micropunches are obtained from dissected brains from control and early-life stressed mice. Following DNA and RNA isolation, gene expression is determined by qRT-PCR while bisulfite treated DNA is amplified and purified products are cloned in a suitable vector allowing identification of recombinant clones by blue/white selection. Correct insert sizes are verified by colony PCR prior to carrying out Big-Dye reaction and processing on a capillary sequencer. Methylation pattern are visualized by appropriate software tools. Click here to view larger figure.

\begin{tabular}{|c|c|c|c|c|c|}
\hline Day 1 & Day 2 & Day 3 & Day 4 & Day 5 & Day 6 \\
\hline $\begin{array}{l}\text { - DNA } \\
\text { extraction: } 4 \mathrm{~h} \\
\text { - Bisulfite } \\
\text { treatement: } \\
15 \text { min } \\
\text { - Bisulfite } \\
\text { conversion: } \\
\mathrm{O} / \mathrm{N}\end{array}$ & $\begin{array}{l}\text { - Clean-up } \\
\text { converted } \\
\text { DNA: } 40 \text { min } \\
\text { - Bisulfite } \\
\text { PCR: } 3,5 \mathrm{~h} \\
\text { - Clean-up } \\
\text { PCR } \\
\text { product: } 15 \\
\text { min } \\
\text { - Ligation: } 15 \\
\text { min + } \\
\text { incubation } \\
\text { O/N }\end{array}$ & $\begin{array}{l}\text { - Clean-up } \\
\text { ligation } \\
\text { products: } 1 \mathrm{~h} \\
\text { - Transformation: } \\
1,5 \mathrm{~h}+ \\
\text { incubation } \mathrm{O} / \mathrm{N}\end{array}$ & $\begin{array}{l}\text { - Colony } \\
\text { selection, } \\
\text { colony PCR } \\
\text { and } \\
\text { identification } \\
\text { of positive } \\
\text { clones: } 6 \mathrm{~h}\end{array}$ & $\begin{array}{l}\text { - Clean-up } \\
\text { PCR } \\
\text { product: } \\
2 \mathrm{~h} \\
\text { - Big-Dye } \\
\text { reaction: } \\
1 \mathrm{~h}+ \\
\text { reaction } \\
\mathrm{O} / \mathrm{N}\end{array}$ & $\begin{array}{l}\text { - Clean-up } \\
\text { PCR } \\
\text { reaction: } \\
1 \mathrm{~h} \\
\text { - Sequencing }\end{array}$ \\
\hline
\end{tabular}

Figure 2. Timeline from DNA/RNA extraction to bisulfite sequencing. 


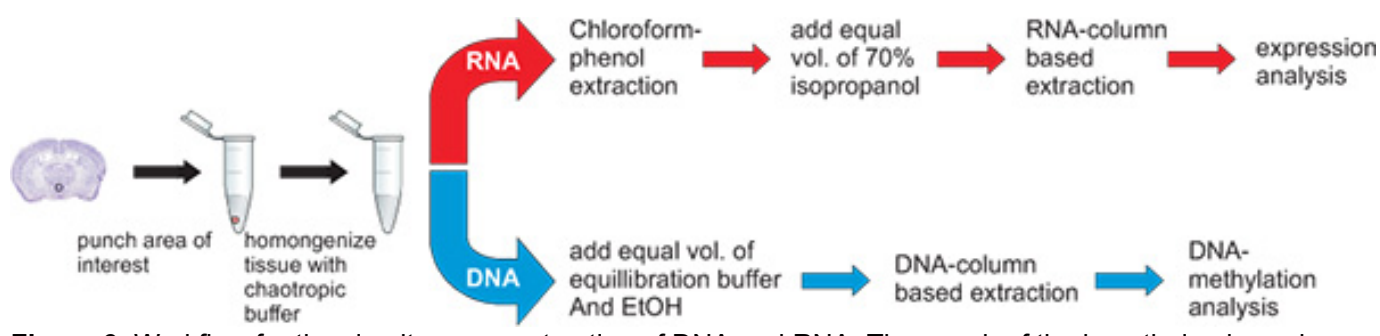

Figure 3. Workflow for the simultaneous extraction of DNA and RNA. The punch of the hypothalamic nucleus paraventricularis, a tiny Avp gene expressing brain region, is placed in $400 \mu \mathrm{l} \mathrm{GTA}$ buffer, vortexed until disrupted and further homogenized by passing through a syringe (29G). The homogenate is then split for the purification of RNA and DNA. The split can be 1:1 or of different proportions depending on the particular experimental question. Homogenates should be processed within a few hours.
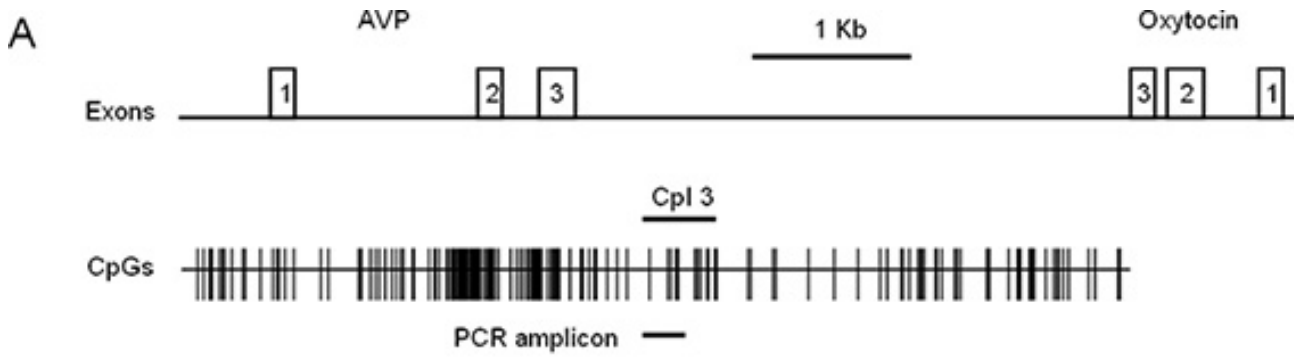

B

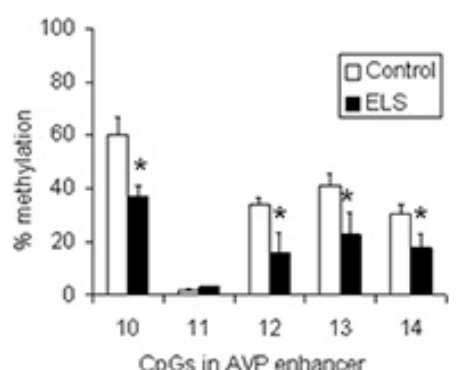

C

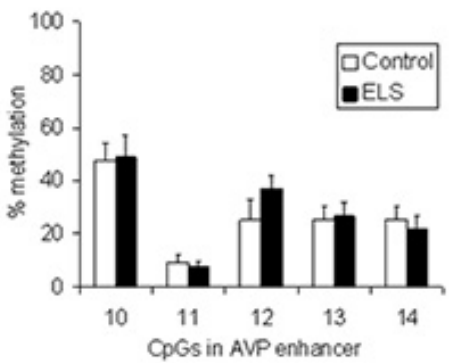

D

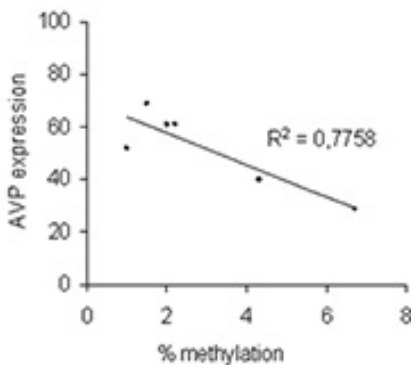

Figure 4. CpG methylation at the Avp locus in 6 weeks old control and ELS animals. (A) Scheme of the Avp and oxytocin genes orientated tail to-tail and separated by the intergenic region (IGR). Exons are depicted by open (numbered) boxes. The distribution of $\mathrm{CpG}$ residues is indicated and size and position of the respective PCR amplicon containing CpG 10 to CpG14 is marked by a bold line. (B) Methylation of the Avp enhancer in the PVN in control and ELS animals $(n=6-8)$. (C) Methylation of the Avp enhancer in the SON in control and ELS animals ( $n=8-10)$. (D) Avp gene expression was correlated with methylation at $\mathrm{CpG10}(n=6)$. Click here to view larger figure.

\section{Discussion}

Epigenetic programming is increasingly recognized as an important mechanism underlying health and disease. Here we present a refined method for the simultaneous isolation of DNA and RNA from micropunches and the subsequent steps to obtain DNA methylation profiles through bisulfite sequencing. The optimized workflow allows convenient analysis of epigenetic programming in the brain in response to environmental stimuli. Moreover, this approach facilitates the investigation of the functional relationship between DNA methylation and gene expression as both are analyzed from the same sample. Finally, animal numbers needed for the experiment can be significantly reduced.

Certain precautions and guidelines should be followed while performing the presented workflow. Considering the extraordinary complexity and heterogeneity of the brain and since methylation and expression pattern may vary in a cell- and tissue specific manner it is of utmost importance that micropunching is performed in a standardized manner. As a case in point, epigenetic programming of Avp is detected in the paravaventriuclar, but not in the supraoptic nucleus (Figure $4 \mathrm{~b}-\mathrm{d}$ ), two Avp expressing regions of the hypothalamus ${ }^{4}$. In this respect, availability of DNA and RNA from the same tissue punch is advantageous as RNA expression of certain tissue specific marker genes can be used in some cases to certify that the correct area was punched. Although micropunching can reduce cellular heterogeneity, it has to be remembered that this approach does not lead to the isolation of single cell types or populations. Additional purification steps might be considered to address this topic.

For bisulfite sequencing optimal primer design for PCR amplification following bisulfite treatment is essential. PCR products exceeding 400 bp in length can be problematic due to the degradation of DNA by the bisulfite treatment. It should be also noted that nested PCR can give biased results if only a few intact templates contribute to the amplification process. Primer pairs that are specific for the modified amplicon should be designed; their sequences should not contain $\mathrm{CpG}$ dinucleotides in order to avoid methylation-biased amplification. In addition, primers 
should contain non-CpG cytosines to prevent amplification of unmodified or incompletely converted DNA. Amplification of some templates may benefit from conducting Hot-start PCR. In any case, suitability of primer pairs should be verified in pilot experiments so as to prevent spoilage of valuable experimental specimens.

Bisulfite sequencing represents a standard method for site-specific methylation analysis as it is able to reliably and precisely detect the methylation of single $\mathrm{CpG}$ residues in an allele-specific manner ${ }^{8}$. Direct sequencing of the PCR product is not advised as mixed methylation of a CpG residue will appear as a C/T double peak in the electropherogram, which can prevent quantification of methylation at the site concerned. For this reason an intermediate cloning step is conducted and several clones are sequenced ( 20-30) to determine the extent of methylation. Pyrosequencing represents an alternative method to quantify DNA methylation. It also utilizes bisulfite conversion and bisulfite PCR but instead of cloning and sequencing the amplicon is subjected to a direct pyrosequencing reaction where the methylation status of a CpG residue is read as a C/T single nucleotide polymorphism that can be easily quantified. Both methods detect similar levels of methylation ${ }^{9}$ but since the cloningstep can be omitted pyrosequencing is more time-efficient. However, depending on the template only 40-100 nucleotides can be sequenced at once so that several rounds of pyrosequencing with different sequencing primer are necessary. This is a critical limitation, given that higher amounts of DNA (about $1 \mu \mathrm{g}$ per reaction) are required, which foreseeable exceed the amounts available from tiny brain tissue punches. Thus initial scanning of regions in the range of several kilobases by pyrosequencing appears less suited as single clone reading. Nevertheless, following on identification of a small region of interest pyrosequencing should be considered.

Collectively, the protocol described above provides an accurate, efficient and streamlined approach for the rapid and cost-effective analysis of brain micropunches for epigenetic changes. Multiple specimens can be processed in a single run and the methods are suitable when running samples from intermediate-sized experiments.

\section{Disclosures}

No conflicts of interest declared.

\section{Acknowledgements}

This work was funded by the Max Planck Institute of Psychiatry and the European Union's Marie Curie Initial Training Network (NINA Contract 238665).

\section{References}

1. Jirtle, R.L. \& Skinner, M.K. Environmental epigenomics and disease susceptibility. Nat. Rev. Genet. 8, 253-262 (2007).

2. Murgatroyd, C. \& Spengler, D. Epigenetic programming of the HPA axis: Early life decides. Stress (Amsterdam, Netherlands)., (2011).

3. Gluckman, P.D., Hanson, M.A., Buklijas, T., Low, F M., \& Beedle, A.S. Epigenetic mechanisms that underpin metabolic and cardiovascular diseases. Nat. Rev. Endocrinol. 5, 401-408 (2009).

4. Murgatroyd, C., et al. Dynamic DNA methylation programs persistent adverse effects of early-life stress. Nat. Neurosci. 12, 1559-1566 (2009).

5. Murgatroyd, C., Wu, Y. Bockmühl, Y., \& Spengler, D. Genes learn from stress: How infantile trauma programs us for depression. Epigenetics. 5, (2010).

6. Paxinos, G. \& Franklin, K.B.J. The Mouse Brain in Stereotaxic Coordinates, Compact: The Coronal Plates and Diagrams: Compact. The Coronal Plates and Diagrams., Elsevier Science Publishing Co Inc., (2008).

7. Bettscheider, M., Murgatroyd, C., \& Spengler, D. Simultaneous DNA and RNA isolation from brain punches for epigenetics. BMC research notes. 4, 314 (2011).

8. Clark, S.J., Harrison, J., Paul, C.L., \& Frommer, M. High sensitivity mapping of methylated cytosines. Nucleic Acids Res. 22, $2990-2997$ (1994).

9. Reed, K., Poulin, M.L., Yan, L., \& Parissenti, A.M. Comparison of bisulfite sequencing PCR with pyrosequencing for measuring differences in DNA methylation. Anal. Biochem. 397, 96-106 (2010). 